\title{
Charles Péguy y su lectura cristológica de la antigüedad clásica
}

\author{
Agostino Molteni \\ Instituto de Teología \\ Universidad Católica de la Santísima Concepción \\ amolteni@ucsc.cl \\ (D) ORCID: 000-0001-5392-0183
}

\begin{abstract}
Resumen: La fe y la teología no pueden cerrarse frente a reflexiones laicas que las puedan enriquecer. En este artículo se quiere volver a proponer la lección de Charles Péguy, que ofrece la posibilidad de redescubrir el aporte que una lectura cristiana de la antigüedad clásica puede ofrecer a la fe y a la teología de nuestra época. En especial modo nos limitaremos a la lectura cristológica que Péguy hace de la heredad clásica, que puede mostrar distintos aportes a la cristología.
\end{abstract}

Palabras clave: Charles Péguy, antigüedad clásica, cristología, teología.

Abstract: Faith and theology should not be closed to lay reflections that can enrich them. In this article, we propose a different understanding of Charles Péguy which offers the possibility of rediscovering the contribution that a christian reading of classical antiquity can offer to the faith and theology of our time. We will limit ourselves to Péguy's christological reading of the classical inheritance that can offer different contributions to Christology.

Keywords: Charles Péguy, classical antiquity, christology, theology.

\section{INTRODUCCIÓN}

En los primeros siglos de la fe cristiana, entre los Padres existieron posturas de valoración positiva del mundo de la antigüedad clásica junto a las de condena de aspectos peculiares. La misma fe y teología no dejaban de nutrirse de "las premoniciones del cristianismo ya presentes entre los paganos" ${ }^{\prime}$. Si esto fue verdadero para los Padres, con el pasar

1 Entre otros estudios, cf. los clásicos: H. RAHNER, Miti greci nell'interpretazione cristiana (Il Mulino, Bologna 1971); J. DANIELOU, Mensaje evangélico y cultura helenistica: siglos II $y$ III (Ediciones Cristiandad, Madrid 2002) 40-41. 
de los siglos "cristianos" se ha visto un cierto debilitamiento de la relación entre la fe-teología cristiana y la antigüedad clásica. En los tiempos actuales, aunque en teología desde el siglo pasado, se ha iniciado una interesante apertura hacia la literatura ${ }^{2}$ y si se debe reconocer que ha existido un trabajo de organización de los materiales que muestran esta relación ${ }^{3}$, nos parece que ha faltado pensar desde dentro de la fe los posibles aportes que la antigüedad clásica puede ofrecer a la misma fe y teología cristiana actual.

En este sentido, y es la intención de este artículo, volver a proponer la lección laico-cristiana de Charles Péguy ${ }^{4}$ ofrece la posibilidad de reconocer estos posibles aportes. En especial modo nos limitaremos a la lectura ${ }^{5}$ cristológica que Péguy hace de la heredad clásica. Aunque está claro que no era un teólogo profesional ${ }^{6}$, su lectura puede mostrar distintas sugerencias a la cristología de nuestro tiempo.

Con el simple sensus fidelium del cristiano laico, la fe de Péguy ha coronado su interés y entrañable afecto por la antigüedad clásica ${ }^{7}$ que, iniciado desde su juventud, se ha acentuado después de su reencuentro

2 La bibliografía es abundante. Entre otros señalamos: M. BALlarini, Teologia e letteratura (Morcelliana, Brescia 2015); Concilium, "Literatura y teología", n. 373, 2017; A. Gesché, "La théologie dans le temps de l'homme. Littérature et révélation”, en J. VermeYlen (éd.). Cultures et théologies en Europe. Jalons pour un dialogue (Cerf, Paris 1995), pp. 109-142.

3 Las obras que tenemos son más bien de compilación de materiales. Entre otras, señalamos algunos clásicos: H. RAHNER, Miti greci nell'interpretazione cristiana (IL Mulino, Bologna 1971), C. Moeller, Sabiduría griega y paradoja cristiana (Encuentro Madrid 2008); J. Danielou, Mythes pä̈ens, mystère chrétien (Fayard, Paris 1966); H. U. von Balthasar, Gloria. Una estética teológica. 4. Metafísica. Edad Antigua (Encuentro, Madrid 1986).

4 Hablamos de lectura "laico-cristiana" porque Péguy se ha considerado siempre un laico que en el reencuentro con la fe ha visto confirmado su pensamiento anárquico-socialista-dreyfusard.

5 Sobre el concepto de "lectura", Péguy escribía: "La lectura es la coronación de un texto (o la de-coronación)": C. PÉGuY, Clio. Dialogue de l'histoire et de l'âme païenne, en Euvres en prose complètes III, 1008.

6 Hay que señalar lo que dice H. U. vON BALTHASAR de modo extremadamente significativo cuando afirma que Péguy es quien "tensa el arco y apunta a Ireneo", pues "aquí y solo aquí [en Péguy] la teología ha vuelto a su primer puerto, Ireneo de Lyon” (Gloria. 3. Estilos laicales, Madrid 1986) 405; 407.

7 Remitimos a la imprescindible y fundamental obra de S. Fraisse, Péguy et le monde antique (A. Colin, Paris 1973). 
con la fe cristiana ${ }^{8}$ llevándolo a exaltar la pureté antigua representada por Grecia y Roma'. Un testimonio grandioso es dado en Ėve en que la antigüedad pagana es presentada como salvada y coronada por Cristo, que es el heredero de este mundo. En este mismo sentido, este mundo pagano ha trabajado para Cristo ${ }^{10}$.

Hay que notar de antemano que del mundo antiguo a Péguy le ha interesado solo Grecia y Roma.

\section{GRECIA}

Péguy cuando habla de la pureza-pureté de los antiguos griegos se refiere al pensamiento de Homero y de los trágicos, no incluye al de los filósofos.

\subsection{La polis griega y el Zeus hospitalario}

Si bien el tema de la ciudad puede ser considerado transversal en la visión de Péguy sobre el mundo antiguo, para él "los griegos han aportado la ciudad"11. Es de la ciudad antigua que se puede hacer la ciudad cristiana, la civitas $D e i^{12}$, pues la primera era sana en su constitución dado que "nada era tan puro como la ciudad antigua"13. De este modo, la ciudad antigua es "como una figura, como una prefiguración de la ciudad de Dios"14 $y$, por tanto, la ciudad que Cristo engendra no es una invención totalmente nueva y ajena a la constitución de la polis griega (y de la civitas romana).

El tema de la ciudad antigua es importante para la temática cristológica que nos interesa. Si, como veremos, los dioses griegos son indefendibles, Péguy salva de esta condena solo al Zeus hospitalario y cívico

8 H. U. von Balthasar afirma que, según Péguy, Cristo "vino para coronar el orden de la naturaleza con el orden de la gracia, pero no con la humillación del orden natural" (Gloria. 3. Estilos laicales, 419).

9 Cf. C. PÉGuY, Clio, Dialogue de l'histoire et de l'âme païenne, 1157.

10 Cf. C. PÉGuY, Evve, en CEuvres poétiques et dramatiques (Gallimard, Paris 2014) 1301-1327.

11 C. PÉguY, Lettres et entretiens (Editions de Paris, Paris 1954) 147.

12 Cf. C. Péguy, Clio, Dialogue de l'histoire et de l'âme païenne, 1157.

13 C. PÉGuY, Clio, Dialogue de l'histoire et de l'âme païenne, 1155.

14 C. PÉguy, Note sur M. Descartes, 1371. 
que no es el Zeus olímpico ${ }^{15}$, sino el Zeus de los huéspedes ${ }^{16}$, puesto que "acoge al miserable como una figura de Jesucristo"17. El Zeus hospitalario es el dios para el cual ningún ciudadano debe ser excluido de la ciudad universal ${ }^{18}$. Y, mientras el Zeus olímpico es el príncipe de los dioses, el Zeus hospitalario es "el príncipe de los hombres (prince des hommes)" 19 , es decir, no se distancia ni se separa de los hombres, no es de otro mundo diferente del que viven y sufren los hombres, sino que es como el primero que sufre con quien sufre, es el primer mendigo con quien es mendigo. La grandeza del Zeus hospitalario consiste en conmoverse hacia los hombres y sufrir por las mismas infelicidades humanas. Es un Dios capaz de sufrir, cuyo poderío no es el de disponer con facilidad de la suerte del hombre, sino de adquirir el poder de sufrir. Es la imagen de Cristo mismo.

\subsection{Edipo rey, el suplicante}

En la figura de Edipo rey, presentada en la tragedia de Sófocles, Péguy ve un aporte de pensamiento cristológico muy importante para la reflexión cristiana.

Para entender esta importancia, hay que retomar un texto que, antes de su reencuentro con la fe, publica en 1905, Les Suppliants parallèles, donde hace un paralelismo entre la súplica de los antiguos y la súplica de los obreros de san Petersburgo que, en aquel mismo año, reunidos frente al Palacio de Invierno y guiados por el pope Gapón, suplican al zar apiadarse de su miseria económica. Lo que conmueve a Péguy es que en Rusia y en la tragedia de Edipo es el pueblo entero, compuesto de viejos y niños, quien está arrodillado frente al rey. En este punto afirma que Edipo, respondiendo al coro del pueblo que le suplica liberarlo de la peste, "llora por la ciudad"20. Y, vinculando el llanto de Edipo con el misereor super turbam de Jesús (Mc 8, 2), afirma que en este llanto consiste la perfección y la pureza de la súplica y lamentación antigua. Edipo, quien es el suplicado, se hace suplicante con los suplicantes, participa de su misma tragedia transformándose en uno de ellos, pues no los conside-

\footnotetext{
C. PÉGuY, Clio, Dialogue de l'histoire et de l'âme païenne, 1158.

Cf. C. PÉguY, Clio, Dialogue de l'histoire et de l'âme païenne, 1163.

C. PÉGuY, De Jean Coste, en Euvres en prose complètes I, 1034.

Cf. C. PÉguY, Clio, Dialogue de l'histoire et de l'âme païenne, 1004-1005.

C. PÉGuY, Clio, Dialogue de l'histoire et de l'âme païenne, 1164.

20 C. PÉGuY, Les suppliants parallèles, 322.
} 
ra como inferiores, no los deprecia, no se separa de la ciudad. Es más, no considera una pérdida hacerse suplicante con ellos, ni tampoco considera una condescendencia de un plano superior, divino, el asumir en su carne, en su llanto, "la común suplicación cívica"21. Aunque este texto es de 1905 y Péguy aún no se ha declarado oficialmente católico, la referencia a la com-pasión de Cristo hacia el pueblo sufriente es para él la fórmula de la suplicación cristiana, mejor dicho, de la lamentación mesiánica ${ }^{22}$.

Hay otro aspecto interesante en este tema de la súplica antigua que alcanza su cumbre en la "más admirable de todas, la súplica del viejo Príamo a los pies de Aquiles"23. En esta súplica no es el suplicado quien tiene la altura de la situación y del dialogo, sino el suplicante. El suplicado es solo un hombre feliz, que "tiene una bella situación", es un rey, un jefe, un vencedor en la guerra, alguien que tiene alguna dominación aparente y que, en tiempos de paz, es rico, poderoso. En este sentido, el suplicado no tiene ninguna grandeza para los griegos, es más, es un "hombre que se debe compadecer", ya que no puede hablar, sino que en nombre de su felicidad, "lo que es poco, lo que es nada, lo que no es una ventaja para los griegos" 24 puesto que el suplicado no representa a nadie, sino solo su felicidad. Como dice el versículo del Magnificat: Deposuit potentes; et exaltavit... que Péguy cita ${ }^{25}$, los poderosos son nada. Si Dios mismo fuese feliz solo de su felicidad divina no sería nadie. Solo un Dios que representa a los hombres, que es capaz de vivir la súplica humana es interesante: el suplicante "representa y no es solo sí mismo"26.

A estas consideraciones Péguy añade la afirmación de que la grandeza del suplicante consiste en ser moldeado por los dedos de los dioses, "esculpido en su materia plástica" como una estatua ${ }^{27}$. De este modo, participa de una especie "de filiación, de una adopción [...] Se ha vuelto hijo de los dioses y ellos lo han tomado como un padre, le han conferido su propia ciudad" por una especie de "segunda concepción

\footnotetext{
21 C. PÉGuY, Les suppliants parallèles, 322.

22 Péguy hace notar cuan perfecta es la lamentación de Jesús sobre la ciudad de Jerusalén que será desolada (Mt 23, 37-39). Cf. C. PÉGuY, Les suppliants parallèles, 322.

23 C. PÉGuY, Les suppliants parallèles, 345. Ver también C. PéGuY, Note sur M. Bergson, en Euvres en prose complètes III, 1250-1251.

24 C. PÉGUY, Les suppliants parallèles, 346.

25 C. PÉGuY, L'Argent, 815.

26 C. PÉGuY, Les suppliants parallèles, 346.

27 C. PÉguY, Les suppliants parallèles, 348.
} 
(enfantement)" 28 . Probado y ejercitado por los dioses, el suplicante es promovido, ascendido a hijo.

Por estas razones, el suplicante desdichado es "el embajador de un gran rey" que le confiere no una ascensión o una elevación (Péguy dice que aquí no es oportuno usar este lenguaje cristiano), sino una "mutación cívica, una promoción, un nuevo derecho de ciudad, de ciudadanía" 29 . La misma desgracia de Edipo es una promoción, ya que se le confiere el derecho a ser ciudadano de una ciudad singular, superior, la de los dioses que sufren el destino. Es esto lo que hace el valor único de Edipo rey "que es una historia de promoción [...] que es un símbolo eminente que representa la realidad antigua: que la desgracia es una promoción”. Edipo es un promovido, pues en el inicio de la tragedia "era un rey, es decir, un hombre ordinario y vulgar y, por el ministerio de la desgracia, por el no éxito del acontecimiento [...] ha sido promovido a la dignidad de suplicante" ${ }^{30}$. El sufrimiento, la desdicha no son, por tanto, una disminución de la realeza de Edipo, sino que lo promueven a ser un hombre común, infeliz, o sea, un suplicante en la ciudad de los suplicantes. La tragedia griega es, por tanto y propiamente, "la tragedia de la suplicación” 31 , es decir, la manifestación de la promoción del hombre. Lo que es interesante en Edipo rey no es saber quién es el culpable de la peste en Tebas, sino "quién será el promovido, quién será el desgraciado, quién será el suplicante" ${ }^{2}$. Edipo, que había iniciado como rey, ha sido promovido a suplicante, hombre con los otros hombres ${ }^{33}$. Recordando la inolvidable representación teatral de Edipo rey a la que había asistido en el famoso teatro romano de Orange en 1894, Péguy se conmueve cuando ve al actor que interpretaba a Edipo, Mounet-Sully, al final de la tragedia, bajar de la escena y marcharse por un sendero entre los campos igual al que hacen los campesinos y los transeúntes, "el camino vecinal de una provincia francesa”. Edipo, que había entrado en la ciudad como rey revestido de púrpura y de oro, al final, se marcha como un suplicante "por un camino lleno de piedras puntiagudas" 34 , promovido

\footnotetext{
28 C. PÉGuY, Les suppliants parallèles, 347.

29 C. PÉGUY, Les suppliants parallèles, 349.

30 C. PÉGuY, Les suppliants parallèles, 350.

31 C. PÉGuY, Les suppliants parallèles, 350.

32 C. PÉGuY, Les suppliants parallèles, 351.

33 Cf. C. PÉGuY, Les suppliants parallèles, 352.

34 C. PÉGUY, Les suppliants parallèles, 352.
} 
al derecho de otra ciudad, la de los hombres que mueren. Caminar por los caminos de tierra de los hombres es para Edipo, el rey, su coronación y promoción.

La "encarnación" de Edipo, el hecho que llore por la ciudad, el hecho de que asuma la suplicación común, la de todos los hombres, la que nace de la infelicidad, lejos de ser de modo platónico un rebajamiento y una disminución de su poderío, una pérdida de prestigio para su naturaleza de rey, es una promoción a la ciudad de los hombres. La condición humana de suplicante, de infeliz es, por tanto, una ventaja para Edipo, el rey. Solo comparándose con la infelicidad humana puede ser el rey de la ciudad de los hombres. De otra forma, sería solo un rey que representa su felicidad de soberano todopoderoso y feliz, se representaría solo a sí mismo, lo que es nada.

Péguy, en Edipo rey es como si encontrara una cristo-lógica precristiana. En su lectura se puede ver una semejanza de la historia de Edipo con el camino humano de Cristo, así como es relatado en la exhortación (consolatio) cristológica de la carta a los Filipenses (2, 6-9), aunque hay que estar atentos a no querer encontrar un paralelismo rígido y total en todos los aspectos. Cristo entra en el mundo como rey ("siendo de condición divina”) y sale como suplicante ${ }^{35}$. Lejos de representar una disminución para su realeza, la encarnación del Hijo, su kénosis, el "tomar el aspecto de hombre" y ser "encontrado como hombre" sujeto al sufrimiento y a la muerte, su misma obediencia ("obedeciendo hasta la muerte") esculpida por los dedos del Padre, son una promoción, el inicio de su derecho a otra ciudad, a la de los hombres. La encarnación, por tanto, es una promoción para el Hijo, no es un rebajamiento, un empobrecimiento, una degradación de su condición divina, la reducción a un dios menor.

La misma súplica de Cristo, es una promoción, todo lo contrario de la idea moderna de progreso. El progreso cristiano es algo único, el de un Dios que se vuelve suplicante: "Maravilloso progreso para un cristiano: [Cristo] procidit in faciem suam, un Dios caído hacia adelante con el rostro en tierra, postrado sobre la tierra, un Dios, él mismo, humilde, un Dios sumiso en la miseria (détresse) y en la humildad del hombre" 36 .

35 Cf. $\mathrm{Hb}$ 5, 7: "Durante su vida mortal dirigió peticiones y súplicas, con clamores y lágrimas...".

36 C. PÉGuY, Dialogue de l'histoire et l'âme charnelle, 758. 
La oración, la súplica de Jesús postrado en tierra es su maravilloso progreso, su promoción: "Y progresando un poco, cayó rostro en tierra, y suplicaba" (Mt 26, 39). En este punto, Péguy da a entender que ser hombre, para Cristo, es un progreso, una grandeza, un enriquecimiento para su divinidad.

Además, el hecho de que con su encarnación Cristo marcha por los caminos de todos los hombres llenos de piedras puntiagudas, no es una disminución de su condición divina, más bien, es la promoción a rey de otra ciudad, de otro mundo, el de los hombres, y su reino es, por tanto, el del Padre y de los hombres. En la encarnación, Cristo une los dos reinos, el reino de Dios y el reino de la infelicidad y pobreza del hombre y hace de ellos uno solo. Cristo en su sufrimiento y muerte es promovido a rey de los hombres, representante de los hombres, príncipe, o sea, el primero de los hombres delante de Dios. Solo a esta condición Cristo puede ser "exaltado" -promovido con un nombre que está "sobre todo nombre" (Fil 2, 9), el de suplicante.

En este sentido, como Edipo, Cristo es "temible" 37 para los fariseos, para los sumos sacerdotes, para los hombres religiosos, para los cristianos felizmente burgueses, pues representa a un Dios que es afectado por la miseria, el infortunio, la muerte. Cristo es temible para los que Péguy llama los biempensantes porque representa el "escándalo" de un Dios que es afectado por la desgracia del hombre. Cristo no representa solo la felicidad divina, cosa que en sí no interesaría al hombre, sino que representa a todo hombre con su sufrimiento y muerte. A este propósito, Fraisse señala, refiriéndose a la lectura de Péguy de la tragedia griega, que "la muerte de Cristo no es un signo que habla contra Dios, sino a favor de Dios"38. Para Péguy, Cristo es promovido, exaltado por el sufrimiento vivido ("por eso Dios lo exaltó...").

Como en Edipo rey, lo que es interesante no es encontrar un culpable del mal -Dios o el hombre-, sino ver quién será promovido por el sufrimiento, es más, verificar si el sufrimiento afecta a Dios, si lo con-mueve, es decir, si el Dios supuestamente todopoderoso, bueno e infinito es capaz de moverse y con-moverse con los hombres, si es capax hominis, capaz de sufrir lo mismo que el hombre sufre ${ }^{39}$.

37 Cf. C. PÉGuY, Les Suppliants parallèles, 347.

38 S. Fraisse, Péguy et le monde antique, 346.

39 C. PÉGuY, Un poète l'a dit..., en CEuvres en prose complètes II, 855. 


\subsection{Divinos, demasiados divinos: los dioses griegos}

La lectura cristológica hecha por Péguy de Edipo rey (hay un único reino, el del Padre $y$ el de los hombres, sin yuxtaposición ni separación) es confirmada por lo que escribe respecto de los dioses antiguos en Clio, Dialogue de l'histoire et de l'âme païenne, dioses que son indefendibles, exceptuando al Zeus hospitalario. Esta lectura debe ser vista sub specie contrario. Hablando de los dioses, de lo que le falta a los dioses ausentes, es como si remarcara su diferencia infinita con Cristo, Dios presente que es motivo de gozo incomparable para los cristianos ${ }^{40}$.

Ante todo, Péguy está bien atento a distinguir el mundo falso de los dioses griegos que dominan (surplombaient) a los hombres y el mundo humano que no es falso ${ }^{41}$, pues es el de los trabajos, de la tierra, del trigo y de las viñas que describe Homero ${ }^{42}$. De hecho, los dioses no son familiares al hombre, son de otro mundo, no se asocian con él: "El Olimpo y el mundo antiguo no están ajustados (ajustés) uno sobre el otro [...] pues son profundamente desplazados (dcals) y el Olimpo no es la coronación del mundo terrenal" ${ }^{3}$. Los dioses griegos son falsos puesto que no son justos, es decir, no se ajustan al mundo de los hombres. De este modo, no tienen ningún ius-derecho sobre el hombre, no pueden coronar su mundo terrenal, o sea, no pueden acceder al título de reyes de los hombres. Los dioses griegos son falsos porque no son del mismo mundo del hombre, al contrario de Cristo que genera una comunión real, no artificial, pues "la única comunión con los hombres es ser de su mundo" ${ }^{4}$.

Es más, siendo que los dioses solo piensan en dominar al mundo de los hombres, conocen este mundo solo por lo que hacen sufrir a los humanos. De este modo, lo que caracteriza a los dioses olímpicos es la "falta de honor [...] una astucia, una pequeñez, una acidez, una maldad, una felonía, un perjuro constante" ${ }^{45}$. Esta falta de honor en el combate terrenal es lo que descalifica totalmente a los dioses frente a los hombres. El mismo Ulises, el personaje antiguo más despreciable por su combate

\footnotetext{
40 Cf. C. PéguY, Victor-Marie, comte Hugo, en Cuvres en prose complètes III, 188-189.

41 Cf. C. PÉGuy, Clio, Dialogue de l'histoire et de l'âme païenne, 1159.

42 Para Péguy, "el personaje homérico es el hombre de la común especie": S. FraISSE, Péguy et le monde antique, 306.

43 C. PÉGuy, Clio, Dialogue de l'histoire et de l'âme païenne, 1161.

44 C. PÉGuY, Clio, Dialogue de l'histoire et de l'âme païenne, 1158-1159.

45 C. PÉGuY, Clio, Dialogue de l'histoire et de l'âme païenne, 1161.
} 
tramposo y por su victoria obtenida de modo fraudulento, en comparación con los dioses es "de una rectitud total" 46 .

Con cautela se puede comparar de nuevo la exhortación cristológica de la Carta a los Filipenses con lo que Péguy afirma de los dioses griegos. Cristo no ha entrado en este mundo haciéndose distinto, avanzando pretensiones divinas en virtud de sus atributos ontológicos manifestados de modo ostentoso para poder dominar el mundo. Él ha sido de este mundo, lealmente, sin trampas, combatiendo un combate leal, no como Ulises; Cristo ha vivido la misma vida del hombre hecha de miseria, sufrimiento, muerte. Cristo "se ha expuesto y se ha propuesto" ${ }^{7}$, ha pertenecido a la raza de los que combaten con un método leal las batallas terrenales que son una "operación de alegría"48. Cristo no ha entrado en el mundo como si fuera, de manera soberbia, de otro mundo para sobreponerse y dominar el mundo de los hombres ${ }^{49}$. Ha sido justo en cuanto se ha ajustado a este mundo terrenal. De este modo, el mundo de Cristo y de los hombres es el mismo mundo, se trata de una grandeza común. De hecho, hablando de los semidioses cantados por Homero, Péguy afirma que ellos son grandes por su humanidad, "ciertamente no porque su media-sangre de dioses los aventaje, sino, al contrario, es su media-sangre de hombres lo que los aventaja como dioses" 50 .

En este punto, de modo indirecto, Péguy es como si afirmara que la encarnación de Jesús no hace de él un Dios disminuido, que la muerte no es una aminoración para él, para su divinidad, es más, que la muerte es una grandeza para Cristo. Él es "grande" no por su inmortalidad o divinidad, sino por haber compartido la muerte del hombre. No se trata aquí de una paradoja. Es la lógica de la encarnación llevada hasta su significado último, real. Ser hombre y morir no es un empobrecimiento para Cristo, al contrario, es un provecho, un progreso, un enriquecimiento, una exaltación ("Por eso el Padre lo ha exaltado...")

46 C. PÉGuY, Clio, Dialogue de l'histoire et de l'âme païenne, 1161.

47 C. PÉGUY, Note conjointe sur M. Descartes, 1348.

48 C. PÉGUY, De la situation faite au parti intellectuel, en Euvres en prose complètes II, 752.

49 Cf. C. PéguY, Note conjointe sur M. Descartes, 1344.

50 C. PÉguY, Clio, Dialogue de l'histoire et de l'âme païenne, 1161.

51 Hay que notar que el centurión, viendo a Jesús morir, exclama: "Verdaderamente este hombre era hijo de Dios" (Mc 15, 39). Recordamos lo que ha escrito S. WeIL: "Sufrimiento: superioridad del hombre sobre Dios. Fue precisa la encarnación para 
A este respecto, la acusación más grave que Péguy hace a los dioses es que ellos no tienen la triple grandeza del hombre: el riesgo, la miseria y la muerte ${ }^{52}$. De aquí, según Péguy, el desprecio de los griegos hacia sus dioses que "libran batallas eternas, batallas de un amor eterno", dioses que "no son mortales y que, de esta forma, no están revestidos de la más desgarradora grandeza que es la de ser mortales", dioses que, finalmente "no presentan esta grandeza única que le confiere al hombre el hecho de estar incesantemente expuesto", de vivir el riesgo de la posible no réussite del acontecimiento ${ }^{53}$. Son unos dioses que solo libran batallas eternas montados en caballos divinos y, por eso, pueden huir de manera rápida ${ }^{54}$. Se puede decir que, de modo indirecto, Péguy hace entender que Cristo ha librado una batalla que no es eterna como los dioses, sino temporal, ni tampoco ha querido tener la posibilidad de huir de la historia gracias a sus atributos divinos.

Para Péguy está claro que Cristo no ha inventado ex nihilo la triple grandeza humana, o sea, la muerte, la miseria, el riesgo, "sino que ha encontrado para ella su destinación verdadera, les ha asignado su verdadera grandeza, le ha donado su real amplitud" 55 . Cristo es Dios que hereda lealmente la triple grandeza del hombre no como una pena que hay que cumplir, como un costo que hay que pagar para ser hombre. De esta manera, la destinación que Cristo hace de estas grandezas consiste en el hecho de que ha mostrado cómo estas son un provecho para sí mismo y para el hombre y de ningún modo una desgracia, una aminoración, una decadencia. Y la amplitud y ensanchamiento que Cristo hace de ellas se debe al hecho de que las ha vivido en su encarnación y las ha llevado hasta el corazón mismo de Dios, que las ha representado ante el Padre como un verdadero beneficio para él. La grandeza de los dioses es, al contrario, solo una "grandeza humana traspuesta", mitológica, excepto lo que es propio de esta grandeza, es decir, la muerte, el sufrimiento, el riesgo. El mundo de los dioses es mitológico porque está sobre-puesto al mundo de los hombres, está separado de su triple grandeza y los dioses no pueden coronarla puesto que no se nutren de ella: "Su Olimpo no está ligado

que esa superioridad no resultara escandalosa" La gravedad y la gracia (Trotta, Madrid 2007) 119.

52 C. PéguY, Clio, Dialogue de l'histoire et de l'âme païenne, 1164.

53 C. PÉGuY, Clio, Dialogue de l'histoire et de l'âme païenne, 1163-1164.

54 C. PÉGuY, Clio, Dialogue de l'histoire et de l'âme païenne, 1184.

55 C. PÉGuY, Clio, Dialogue de l'histoire et de l'àme païenne, 1164. 
a su mundo, no es un coronamiento nutrido de su mundo, del mismo mundo [...] Es un mundo yuxtapuesto (juxtaposé) en el sentido vertical, es sobrepuesto (superposé)" 56 , es el mundo de una divinidad mitológica que no acepta compararse lealmente con la triple grandeza del hombre. Sin esta imputabilidad histórica, si Dios existiera, para Péguy sería solo materia y objeto estéril de estudio para la "historia de las religiones" 57.

Esto se confirma por lo que Péguy sostiene hablando del significado de la muerte en Homero. El hombre que muere se corona como hombre, pleno de una vida humana, mortal, al contrario de los dioses que carecen de esta plenitud que es la muerte humana. Esta es la desventaja de los dioses, pues la inmortalidad no es una riqueza sino una pobreza, significa carecer de algo, de la muerte: "Es de este cumplimiento, de esta plenitud, que los dioses carecen (manquent). Los dioses carecen de esta coronación que es, en fin, la muerte" 58 . Es por esta razón que los griegos desprecian a los dioses, porque no son finitos y, de este modo, no pueden coronarse en la muerte, al contrario del hombre: "Los dioses no están llenos; es el hombre el que está lleno [...] El hombre que muere está lleno de una vida y también de una eternidad"59. Si relacionamos estas afirmaciones con Cristo, su finitud como hombre, lejos de ser una disminución o una desventaja, le confieren una plenitud, una coronación, una soberanía única ya que Cristo se muestra rey no de un mundo inmortal y eterno, sino del de los hombres que mueren. Y si de lo que carecen los dioses es de "morir jóvenes como Aquiles" 60 y como el joven Simónides ${ }^{61}$, el hecho que Cristo haya muerto joven es una razón ulterior de su grandeza y plenitud. La muerte joven de Jesús es vista por Péguy como un privilegio concedido por el Padre que "había decidido [...] que él muriera en la flaca (maigre) juventud de sus treinta y tres años"62. Si los dioses "carecen de no carecer" 63 como escribe en cursiva Péguy, es decir, carecen de la plenitud de la muerte humana, el

\footnotetext{
56 C. PÉGuY, Clio, Dialogue de l'histoire et de l'âme païenne, 1165.

7 C. PÉguY, Dialogue de l'histoire et de l'âme charnelle, 676.

58 C. PÉGuY, Clio, Dialogue de l'histoire et de l'âme païenne, 1166.

59 C. PÉGuy, Clio, Dialogue de l'histoire et de l'âme païenne, 1166-1167.

60 C. PÉguY, Clio, Dialogue de l'histoire et de l'âme païenne, 1167.

61 Péguy aquí cita el trecho de la Ilíada, IV, 473.

62 C. PÉGuY, Le mystère de la charité de Jeanne d'Arc, en Euvres poétiques et dramatiques, 470.

63 C. PÉguy, Clio, Dialogue de l'histoire et de l'âme païenne, 1168.
} 
hecho que Jesús muere es su perfección como hombre-Dios. Es más, según Péguy, para Jesús su muerte es una coronación-gloria-réussite de su encarnación, porque la toma "en pleno, en plena frente, delante, en su amplitud, así como había tomado toda su vida" y por eso, esta muerte es la suprema "prueba, control, verificación, realización suprema de la encarnación” "64. La pasión y muerte de Jesús son la contraprueba y verificación de hasta qué punto había llegado en su encarnación: "Quien moría como hombre, hasta ese punto como hombre, había estado por tanto bien encarnado humanamente (bien incarné homme)" 65 .

Todo lo dicho hasta ahora encuentra una condensación en una afirmación fundamental de Péguy. En un cierto punto, hablando de Victor Hugo, lector de Homero, afirma que "este sabía lo que estalla por todos lados en Homero: que hay más en un hombre que en un Dios que asombra-sorprende desde lejos (Il y a plus dans un homme que dans un Dieu qui étonne au loin)" "66. Esta afirmación es la clave de lectura decisiva para entender cómo Péguy ha reconocido el acontecimiento de Cristo a la luz de su reflexión sobre la antigüedad pagana. A Péguy, a quien no interesaban los "religiosismos" 67 , de ninguna manera podía agradarle un Dios que asombraba desde lejos por sus atributos ontológicos, por su infinitud, eternidad, omnipotencia, omnisciencia, grandeza, amor, realeza, soberanía.

\section{ROMA}

Aunque cuantitativamente menos presente en su obra respecto de la antigüedad griega, también el mundo romano antiguo ha sido muy importante para Péguy y su reflexión cristológica.

Roma antigua representa para Péguy el "civismo", el fondo de su "reflexión cívica" ${ }^{68}$ o mejor dicho, de su pensamiento cívico-cristiano.

64 C. PÉGuY, Dialogue de l'histoire et de l'âme charnelle, 743.

${ }^{65}$ C. PÉGUY, Dialogue de l'histoire et de l'âme charnelle, 743.

66 C. PéguY, Clio, Dialogue de l'histoire et de l'âme païenne, 1038.

67 C. PÉGUY, Dialogue de l'histoire et de l'àme charnelle, 670.

68 P. Duployé, La religion de Péguy (Slatkine Reprints, Genève 1978) 513. H. U. vON BALTHASAR señala que "la praeparatio evangelica de la antigüedad nunca se presentó a los ojos de Péguy ceñida unilateralmente al aspecto espiritual-filosófico griego, sino vinculada también al aspecto político-jurídico, estratégico, con inclusión de esta esfera aparentemente tan mundana en la gesta redentora del mundo" (Gloria. 3. Estilos laicales, 479). 
Después de un inicial desprecio hacia Roma, hacia el año 1909, se nota un cambio por parte de Péguy que reconoce el valor fundamental del encuentro de la romanidad con la cristiandad. De hecho, Cristo ha salvado a Roma y al mundo entero de la mayor desgracia que pudiera ocurrir al hombre, o sea, "del inicio del mundo moderno que estaba ya presente en los tiempos de la decadencia romana" ${ }^{69}$ que, sin embargo, estaba llena de gérmenes buenos ${ }^{70}$. Este cambio se debe a su pensamiento cristológico $^{71}$. En este sentido, Roma es una "encarnación” que prepara la encarnación de Cristo: "Él [Cristo] iba a asumir la heredad de Roma, iba a coronar aquella encarnación" 72 . La encarnación de Dios en la historia corona la "encarnación" de Roma, su inscripción en lo temporal y en lo terrenal. Una encarnación "tan importante porque carnal, corporal, material, tan importante que nos parece de una importancia excesiva y realmente inquietante" 73 .

\subsection{La pax romana y la destinación temporal de Dios}

La "encarnación” de Roma, el hecho de que haya construido una tierra, un espacio geográfico para el acontecimiento de la encarnación de Cristo, Péguy lo resalta ante todo en la civitas que es Roma, cuyo acto de fundación - ab urbe condita ${ }^{74}$ - es de enorme importancia, pues constituye un inicio de obediencia a la historia, a Clío, y representa la ciudad antigua que parte hacia "una coronación eterna" (éternel couronnement) 75 , la coronación dada por Cristo fundador en la ciudad terrenal, en la historia, de otra ciudad, la civitas Dei ${ }^{76}$. De este modo, "Roma aporta el lugar [...] el habitáculo [...] el hábitat"77, y su civitas, su república, su

69 C. PÉGuY, Dialogue de l'histoire et de l'âme charnelle, 701.

70 En la decadencia antigua de Roma "había más recursos, pues esta podredumbre estaba llena de gérmenes”: C. PÉGuY, À nos amis, à nos abonnés, en CEuvres en prose complètes II, 1301.

71 Si para Péguy, en 1907, la pax romana era el más disgustoso de los equilibrios antiguos, en 1909 es un "cumplimiento, una plenitud": S. Fraisse, Péguy et le monde antique, 376.

72 C. PÉguY, Ève, 1301.

73 C. PÉGuY, À nos amis, à nos abonnés, 1306.

74 Cf. C. PÉGuY, Dialogue de l'histoire et de l'âme charnelle, 630.

75 C. PÉguy, Dialogue de l'histoire et de l'âme charnelle, 638.

76 Cf. C. PÉGuY, Dialogue de l'histoire et de l'âme charnelle, 632.

77 C. PÉGuY, Clio, Dialogue de l'histoire et de l'âme païenne, 1157. 
imperio, su pax romana, son la "cuna" (berceau) temporal de la cristiandad, lugar histórico de su fundación ${ }^{78}$.

Si Péguy había dicho que la encarnación de Roma debía ser reconocida como inquietante es porque se ha realizado a través de la legión, con su espada colonizadora del mundo entero: "Roma aporta Roma, la legión, el imperio, la espada, la fuerza temporal"79. Esta revalorización de Roma está incluida en un pensamiento cristológico, como escribe en 1913, casi en vísperas de la guerra. Hablando del soldado romano, dice que el Cesar "hace la cantidad de tierra temporal" en que todo, arte, leyes, moral, lenguaje, raza, religión y el mismo cristianismo pueden tener un lugar para hacerse entender, para implantarse y engrandecer: "Existe lo temporal y este es esencialmente militar [...] Lo terrenal debe revestirse de un manto militar" ${ }^{80}$. Es la legión romana, es el soldado, es el César que ha producido un espacio terrenal "donde suena la declinación latina, la griega y la declinación hebrea, ya que es el soldado y la legión romana que ha llevado el tabernáculo y el Dios de Israel" ${ }^{\prime 2}$. De este modo, la historia cristiana no corre paralela, al lado de la historia antigua, ya que "el soldado ha medido la cantidad de tierra temporal que es la misma que la tierra espiritual e intelectual", ha medido la tierra "para el pensamiento [griego] y para la fe [hebrea], para la idea [griega] y para Dios [de la Alianza]" 82 .

Lo que aquí más interesa a Péguy es afirmar que si el soldado romano no hubiera procedido a esta inserción temporal, no hubiese medido la tierra, "si el mundo romano no hubiese procedido a esta especie de injerto (greffe) único en la historia del mundo donde Roma proporciona la fuerza y los griegos el pensamiento...", no se entendería "la necesidad de Roma en la finalidad, en la destinación (destination) temporal de Dios" ${ }^{\prime 3}$. Roma afecta la destinación temporal del mismo Dios, ya que era conveniente que existiese el imperio y la fortificación romana para que el mundo cristiano tomara esta forma temporal. Roma es el andamiaje (berceau) exterior, el andamiaje de madera, el andamiaje-cuna anterior que se adapta (épouse) a la forma del barco cristiano y de donde

\footnotetext{
78 C. PÉGuY, L'Argent suite, en Euvres en prose complètes III, 904.

79 C. PÉGuY, Clio, Dialogue de l'histoire et de l'âme païenne, 1157.

80 C. PÉGuY, L’Argent suite, 901-902.

81 C. PÉGuY, L'Argent suite, 902.

82 C. PÉGuY, L'Argent suite, 902.

83 C. PÉGUY, L'Argent suite, 902-903.
} 
el barco será lanzado ${ }^{84}$. Roma fue el molde (moule) establecido por el soldado romano en que históricamente tuvo que implantarse no solo el mundo griego, sino el mismo mundo cristiano para el cual ha sido conveniente esta "encarnación" de Roma.

Esto implica que, si bien es increíble la finalidad de Roma en el mundo temporal, aún más "estremecedora (saisissant) es la finalidad, la destinación (destination) de Roma en el mundo espiritual, es decir, esta necesidad increíble de lo temporal por parte de lo espiritual, esta incapacidad absoluta de lo espiritual a acontecer sino en lo temporal" ${ }^{\prime 2}$. Esto significa que el imperium temporal de Roma fue la cuna temporal de la misma encarnación de Dios y de su ciudad y Dios mismo, si entra en el tiempo, encuentra conveniente encarnarse en un espacio geográficohistórico adquirido por el soldado romano, no en su rol de asolador de ciudades, sino en cuanto agrimensor que mide la tierra y abre las vías latinas para hacer cumplir la ley romana en todo el orbe.

Este pensamiento se fundamenta sobre el hecho de que, ya que lo temporal tiene una irreversibilidad “impregnante" (empreignante)" 86 , Dios mismo encarnándose en el tiempo queda marcado por la dimensión temporal-geográfica. Es más, si no puede existir el acontecimiento de la encarnación más que en lo temporal, la historia no es una desventaja para lo divino, sino que es propiamente una necesidad si Dios no quiere solo asombrar desde lejos, si quiere ser interesante para el hombre. De este modo, para Péguy, lo temporal "comanda y custodia lo espiritual" 87 , ya que lo temporal propicia y proporciona el espacio para que Dios, en su encarnación, pueda vivir, producir, continuar, proseguir, florecer y borbotear, brotar y fructificar ${ }^{88}$. El mismo reino de Dios es incompren-

84 Cf. C. PÉguy, L'Argent suite, 903. El término berceau puede traducirse como cuna. No obstante, en Péguy, que tenía en su escritorio un diccionario de términos náuticos, tiene también el significado de andamiaje en madera que sostiene el casco del navío antes de su lanzamiento en mar abierto. Cf. S. Fraisse, Péguy et le monde antique, 473.

85 C. PÉGuY, L'Argent suite, 904.

86 C. PÉGuY, L'Argent suite, 905.

87 Cf. C. PÉGuY, L'Argent suite, 907.

88 Cf. C. PÉGuY, L'Argent suite, 910. Fraisse, de modo injustificado, lanza en contra de Péguy acusaciones de maquiavelismo político (Cf. Péguy et le monde antique, 394) y acusa a Péguy de una "parcialidad inoportuna, pues quiere anexar a Dios a los intereses de una nación particular, como si los romanos hubieran podido escribir en sus cinturones Gott mit uns [Dios está con nosotros]" (462). Por otro 
sible sin la anterior preformación terrenal, sin la repartición del mundo hecha por Roma. En efecto, esta ha aportado el "lugar" (lieu) y si "Israel nos ha dado a Dios mismo, Roma nos ha dado la única repartición del mundo donde este Dios podía moldear su nuevo Imperio"89, o sea, donde fueron volcados los pensadores griegos, los profetas judíos y los apóstoles de Cristo ${ }^{90}$.

Para esto fue necesario que el mundo antiguo fuera unificado hereditariamente en Roma que lo forzó con la espada en el molde, en el berceau que el soldado romano había medido conquistando la tierra. Todo el espacio geográfico estaba preparado para la encarnación de Dios y, cuando esta acontece, Cristo se vuelve el "heredero de los herederos romanos" $"$, heredero de la encarnación hecha por Roma.

Esto es el pensamiento de Péguy sobre la "encarnación" de Roma. Ahora bien, se podrían hacer varias críticas a esta lectura.

Se podría acusarla de "providencialista" en el sentido de que Dios utilizaría a los hombres para sus finalidades. Sin embargo, Péguy está muy atento en subrayar la libertad humana que no es simple instrumento de lo divino y, por tanto, se podría decir que, para nuestro autor, Dios toma ocasión de los acontecimientos producidos por la libertad humana para cumplir su designio.

Por otro lado, podría surgir la pregunta si hay una especie de determinismo en el modo como Péguy concibe Roma en relación con Cristo (y el cristianismo), es decir, si la libertad de la encarnación no estaría pre-determinada por la encarnación de Roma. Hay que notar que Péguy habla más bien de la "destinación" (finalidad) de $\operatorname{Dios}^{92}$ en relación a la

lado, podría surgir la pregunta si Roma es entendida por Péguy como condición temporal para la justificación del cristianismo y Cristo, por tanto, como justificador de Roma y del imperio. A esto se puede responder diciendo que la lección de Péguy es cristológica, la de la encarnación. Roma es decisiva porque ha hecho una encarnación, una inscripción histórica que ha sido temporal, inscripción que ha sido coronada por la encarnación de Cristo. En este sentido, no es Roma la que corona a Cristo y al cristianismo, sino por el contrario. Es importante notar que esta perfección-coronación está hecha por Cristo con beneficio de inventario, es decir, sin asumir las patologías imperialistas del pensamiento clásico romano.

89 C. Péguy, L'Éve de Péguy, en Euvres en prose complètes III, 1230.

90 Cf. C. PÉGUY, L'Argent suite, 904.

91 C. PÉguy, Ève, 1317.

92 Cf. C. PÉGuY, L'Argent suite, 903. 
"encarnación" de Roma, que es algo distinto de hablar de un "destinohado" al cual estaría sumiso Dios mismo". Para Péguy, desde que Dios ha creado no solo el tiempo, sino la libertad del hombre, él queda vinculado y necesita del tiempo y de esta libertad: "El Creador necesita de su criatura, se ha puesto a tener necesidad de su criatura, nada puede hacer sin ella" ${ }^{44}$. Cristo mismo necesita "un cuerpo, una carne temporal que sea el sostén material, la materia de una idea" 95 , es decir, del Logos, del pensamiento compuesto Padre-Hijo. Es la afirmación ya señalada de la necesidad de lo temporal por parte de lo espiritual, de la imposibilidad que lo espiritual desconozca lo temporal"96 si Dios no quiere ser seulement Dieu y quiere ser hombre. Lo que Péguy afirma es la necesidad de que "la encarnación se presente en el orden del acontecimiento temporal [...] como una coronación carnal, como una historia (culminante, suprema, límite) acaecida a la carne y a la tierra" ${ }^{\text {". }}$. La misma encarnación de Cristo es, de este modo, coronación de la historia de los hombres, no su menosprecio.

Por otro lado, Péguy de ningún modo quiere decir que a causa de la "encarnación" de Roma, el acontecimiento cristiano queda "romanizado" ni menos aún que queda estructurado de forma "aristocratizante" o militarizada, imperialista. La fe cristiana, para Péguy, no toma las formas de pensamiento del Imperio, más bien es una historia distinta de la de Roma. Aunque sea una historia no opuesta a la de Roma ${ }^{98}$, no se produce entre ellas una coincidencia. Péguy sabe distinguir: "Hay un reino humano y uno cristiano, un reino del hombre y el reino del cristiano [...] y hay una discontinuidad entre ellos"99. En este sentido, Péguy no olvida las atrocidades cometidas por la Roma antigua, "ciudad de masacres y de proscripciones", de "matanza y guerra civil [...] de sangre púrpura y de delaciones" ${ }^{100}$. En muchas estrofas hablará de los manquements

93 Cf. S. Fraisse, Péguy et le monde antique, 465.

94 C. Peguy, Le Porche du Mystère de la deuxième vertu, 715.

95 C. PÉGuY, À nos amis, à nos abonnés (CEuvres en prose complètes II, 1306).

96 C. PÉGuY, L’Argent suite, 904. Cursiva nuestra.

97 C. PÉGuY, Victor-Marie, comte Hugo, 235. Cursivas nuestras.

98 Péguy insistirá por más de ciento y cincuenta estrofas en su Eva que se trata de la misma (même) historia terrenal, la del mundo y de Roma y la de la fe cristiana; sin embargo, la cristiana será otra (autre) historia en la misma historia terrenal. Cf.

C. PÉGuY, Quat rains non retenus d'Ève, 1458-1474.

99 C. PÉGuY, L'Argent suite, 973.

100 C. PÉGUY, Quat rains non retenus d'Ève, 1507-1509. 
de Rome, de los "incumplimientos de Roma"101 que, siendo tentativas inconclusas, han podido ser coronadas por Cristo, pues "solo quien carece de algo puede ser coronado" 102 .

Finalmente, sería legítimo preguntarse si, en la lectura de Péguy, Roma concurre en auxilio de Cristo (y del cristianismo). Seguramente, para Péguy la salvación del hombre consiste en el encuentro de dos libertades, la de Dios y del hombre. Si el hombre falla a Dios, Dios falla al hombre, es decir, se produce un "desastre doble" 103 , el de la oeconomia salutis divina y el de la oeconomia humana: "El fallo del hombre hace fallar a Dios" 104 . Hay, por tanto, como un cambio en la creación, ya que ahora "el Creador depende de su criatura, ha soportado ser puesto, se ha dejado poner a este nivel [...] hay un Dios que ha abdicado en las manos de cada uno de sus súbditos el poder supremo. Dios necesita del hombre"105. Esta necesidad se debe entender más bien como una conveniencia: el Padre, después del pecado original, desea volver a tener al hombre como aliado, le conviene que no fracase su oeconomia de alianza con el hombre.

\section{Conclusiones}

Hablar, como hace Péguy, de Cristo heredero indica que no se puede entender la lógica de la encarnación y redención de Cristo sin la valoración de la antigüedad clásica. El axioma cristiano gratia perficit naturam non destruit es propiamente un dogma cristológico. Pensando cómo realizar su encarnación redentora, Cristo ha ascendido no solo la "gran gracia" de su raza de pensamiento hebreo ${ }^{106}$, sino que ha coronado, sin eliminarlas, las "destinaciones temporales" del mundo antes de Cristo, ya que el ciudadano de la ciudad pagana es "una prefiguración del fiel"107. Si Cristo, según Péguy, ha sido "primus non (profecto) inter pares, sed primus tamen inter alios (primero, en realidad, no entre los iguales, sino, al contrario, entre otros)" ${ }^{108}$, esto significa que no ha menoscabado los

\footnotetext{
101 C. PÉguy, Ève, 1322.

102 C. Péguy, Ève, 1325.

103 C. Péguy, Note sur M. Bergson, 1261.

104 C. PÉGuY, Note sur M. Bergson, 1261-1262.

105 C. Péguy, Le Porche du Mystère de la deuxième vertu, 713; 715.

106 C. PÉguY, Note conjointe sur M. Descartes, 1333.

107 C. Péguy, L'Éve de Péguy, 1229.

108 Cf. C. PÉGuY, Dialogue de l'histoire et de l'âme charnelle, 633.
} 
aportes de humanidad que le ofreció la pureté humana de los antiguos paganos. En este sentido, si por un lado es extremadanamente necesario injertar a Cristo en el pensamiento hebreo, por otro lado, pensamos que la cristología y la misma fe cristiana puede enriquecerse con una lectura cristo-lógica de la antigüedad clásica.

Esto no significa afirmar que en la antigüedad clásica hay pre-revelaciones de un Cristo eterno (gnóstico), de modo que se eliminaría la novedad de Cristo. Como ya hemos señalado, no hay coincidencia entre la figura de Cristo y las figuras de la antigüedad clásica. Lo que hay en algunas de estas figuras es un cierto tipo de pensamiento que puede ser coronado-salvado por Cristo. Sin embargo, lo nuevo aportado por Cristo, que es su misma presencia, no rebaja ni disminuye a Edipo, a la pureza antigua, a la polis griega y a la civis y "encarnación" romana. En este sentido, y como ejemplo, Péguy deja que Edipo sea Edipo y Cristo sea Cristo. Sin embargo, afirma que la lógica con que Cristo ha cumplido su encarnación como verdadero hombre, corona y perfecciona la historia humana de Edipo, su humanidad, mejor dicho, su pensamiento. Con esto Péguy no elimina de ningún modo lo "secular" y no le hace cumplir a la razón laica un salto indebido en la fe, es decir, no traslada fraudulentamente a Edipo hacia la fe cristiana. Más bien muestra que el pensamiento-razón de Edipo era un tipo de pensamiento disponible para ser coronado por el pensamiento de Cristo (1 Co 2,16) en su encarnación y redención. En este punto, la teología puede valorar el aporte de la razón humana a la fe que corona y no remueve-elimina el sano pensamiento laico. Es uno de los "dogmas" predilectos de Péguy, el que no se debe rebajar la razón humana para enaltecer la gracia: "Aquellos que toman distancia sobre el mundo, rebajando al mundo, no se elevan. Solo aquellos que dejan al mundo a la altura en que está, desde allí suben y ganan altura” ${ }^{109}$.

A Péguy le interesa ante todo la humanidad, mejor dicho, el pensamiento clásico antiguo en que encuentra prefiguraciones del mismo pensamiento de Cristo que "vino entre los suyos" (Jn 1, 11), es decir, vino a coronar-cumplir un tipo de pensamiento que no era opuesto al suyo, sino que se había mostrado capax hominis, capaz de ser hombre leal. Por ello, este pensamiento fue capaz de ser coronado por el de Cristo que, a su vez, había demostrado ser capax hominis de modo leal, sin ayudas fraudulentas divinas. En este sentido, la antigüedad clásica le interesa a

109 C. PÉGUY, Note conjointe sur M. Descartes, 1365; 1367. 
Péguy para mostrar un tipo de pensamiento que pudo ser coronado por el de Cristo cuando se hizo lealmente hombre. En este punto está precisamente el aporte cristológico de la antigüedad clásica: ella mostró una humanidad, un pensamiento de hombre bien encarnado, de modo leal.

La reivindicación de la antigüedad clásica no está hecha por Péguy en contra del mundo moderno como si fuera una vuelta mítica y romántica al pasado. En la antigüedad clásica, y esto quiere decir Péguy, había un pensamiento que era capax Dei, más específicamente capax Christi, en cuanto era un pensamiento capax hominis. En este sentido, hay que notar que Péguy no está a priori en contra del mundo moderno, ni quiere legitimar sus propias comprensiones de lo que debe ser el mundo moderno. Al contrario, reconoce que también en el mundo moderno hay un tipo de pensamiento que es capaz de ser coronado por la gracia cristiana. Por ello, por ejemplo, puede decir que en el mundo moderno hay "buenos ateos que la gracia cristiana puede hacer buenos cristianos [...] mientras de los malos ateos la gracia no podrá jamás hacer buenos cristianos" ${ }^{110}$. Los buenos ateos son los que no se atrincheran detrás de un pensamiento ya-hecho, pre-fijado, como lo hacen los malos ateos. Además, en el mismo sentido, puede escribir que "si uno es librepensador, pero no entrega su plaza de sitio, es un pequeño sobrino de Juana de Arco. Y aquel que cede su plaza de sitio es un bastardo, un cabrón (salaud), aunque fuera el sacristán de su parroquia (y aunque tuviera todas las virtudes). Me importan un bledo sus virtudes"111. Los ejemplos se podrían multiplicar con facilidad.

Esto se comprende por la lección que Péguy había aprendido de su maestro Bergson, quien le había enseñado que solo un pensamiento que no estuviera ya-hecho (tout fait), es decir, un pensamiento no sistemático, de sistema, podía ser coronado por la gracia cristiana. Por ello, su oposición a cierta parte del mundo moderno se debe a su rechazo del pensamiento dominante en la modernidad, un pensamiento que ya no es "bergsoniano", pues está ya-hecho, imposible de ser coronado por Cristo. En este sentido, Péguy defenderá siempre a Bergson cuyo método, para él, es "el único que permite entrar en la inteligencia del dogma cristiano"112.

110 C. PÉGuY, L'Argent suite, 956.

111 C. PÉGuY, L'Argent suite, 929.

112 C. PÉguY, Note conjointe sur M. Descartes, 1323. 
Para Péguy hay, por tanto, un pensamiento que puede ser heredado y recapitulado con beneficios de inventario por Cristo, el de la antigüedad clásica, y otro que no se deja recapitular, que no quiere ser coronado por la gracia, el de una cierta parte del mundo moderno. Si la fe cristiana reconoce a Cristo como recapitulador $(\mathrm{Ef} 1,10)$ de modo que "no hay griego ni judío [...] sino Cristo es todo y en todos" (Col 3, 11), la fe cristiana vive del mismo pensamiento de Cristo, es recapituladora. En este sentido, para Hugo Rahner "Dios ha proferido su revelación en el corazón de un mundo que es el del espíritu griego y del imperio romano", de modo que "en el seno de la Iglesia será siempre acogida la herencia helénica y romana, siempre pronta a prorrumpir en un nuevo nacimiento que florezca en una más bella juventud". De hecho "en la rígida delimitación obrada por la carne del Logos hecho hombre reside el explosivo e ilimitado [...] abrazo de todo lo que de verdadero ha sido pensado y cumplido en el largo recorrido de la historia y en las profundidades del hombre"113. Siguiendo la lección de Walter Benjamin (que estimaba mucho a Péguy ${ }^{114}$ ) "nada de lo que una vez haya acontecido ha de darse por perdido por la historia" y a esta hay que pasarle "el cepillo a contrapelo"115, la fe cristiana y la teología deben hacer "obra de liberación en nombre de las generaciones vencidas" 116 por el historicismo. En este sentido, la fe y la teología no deben dejar que la antigüedad clásica sea vencida, es decir, sea fichada y enterrada como en un cementerio por parte de un historicismo teológico que Péguy ha condenado siempre. La fe cristiana y la teología deberían "permanecer situadas en la misma raza carnal y espiritual, temporal y eterna” y, desde allí, "evocar simplemente a los antiguos" 117 . Si, como afirma Walter Benjamin, es falso afirmar, como hace el historicismo, que "un hecho es ya histórico por ser causa" ${ }^{118}$, la fe cristiana y la teología deben reconocer que "existe una cita secreta entre las generaciones que fueron y la nuestra" y que "el pasado

113 H. RaHner, Miti greci nell'interpretazione cristiana, 5-6.

114 Escribe Benjamin a su amigo Scholem: "He vuelto a leer algo de Péguy. Aquí percibo un lenguaje de un increíble parentesco con el mío. Hasta diré: nada de lo que se ha escrito me ha jamás afectado por tanta proximidad, por tanta comunión": W. T-G. Scholem, Correspondance (Aubier-Montaigne, Paris 1979) 197.

115 W. Benjamin, Tesis sobre la historia y otros fragmentos (UACM-Itaca, México 2008) tesis III, 37.

116 W. Benjamin, Tesis sobre la historia y otros fragmentos, tesis IX, 44-45.

117 C. PÉguY, Clio, Dialogue de l'histoire et de l'âme païenne, 1177.

118 W. Benjamin, Tesis sobre la historia y otros fragmentos, apéndice, 58. 
lleva consigo un índice temporal mediante el cual queda remitido a la redención" ${ }^{119}$. Si la fe y la teología viven del pensamiento recapituladorredentor de Cristo, no pueden considerar ajena la misión de "redención" de la antigüedad clásica. "Redención" que debería hacerse mostrando el aporte que el mundo antiguo ha ofrecido a Cristo como materia prima para pensar cómo cumplir su encarnación redentora.

Finalmente, la fe cristiana y la teología deberían abrirse a los aportes literarios de la antigüedad clásica ${ }^{120}$, pues sus páginas tienen, como decía Marcial, el sabor del hombre (que Cristo ha encarnado): "Aquí no encontrarás ni centauros, ni gorgonas, ni harpías; mis páginas saben a hombre (hominem pagina nostra sapit)"121. Y si, para Péguy, Cristo ha cumplido en todo (menos en el pecado) la famosa afirmación de Terencio: Homo sum; nibil humani a me alienum puto ${ }^{122}$, no se trata, como sostiene Moeller de "bautizar las grandes obras creadas antes de la venida de Cristo", ni de "sustituir los símbolos paganos por nuevas representaciones de la vida"123. Esto sería olvidar la lección de Péguy sobre la lectura donde se trata de que "cada tipo de pensamiento sea recogido en su punto, en su akné, en su más alta y perfecta madurez" ${ }^{124}$. De hecho, para él, "todas las grandes metafísicas son lenguajes de la creación y a este título son irremplazables, no pueden ser sustituidas" 125 . Esto implica que no se pueden encerrar a las expresiones literarias de la antigüedad "en el atrio de los gentiles sin permitírsele el acceso al santuario" ${ }^{126}$ de la fe y de la teología que, al contrario, deben reconocer $\mathrm{el} \mathrm{akm}$ de estas expresiones irremplazables. Al igual que para Péguy, estas representaciones de la humanidad antigua y de su pensamiento pueden muy bien ser considera-

119 W. Benjamin, Tesis sobre la historia y otros fragmentos, tesis II, 36.

120 Concordamos con la afirmación que "un estudio más profundo de los antiguos revela que el mundo de la poesía y el de la filosofía se hallan muy separados el uno del otro" (C. Moeller, Sabiduría griega y paradoja cristiana, 26). Sobre la importancia de la literatura (y del arte) para la fe cristiana, cf. Gaudium et spes 62.

121 Marcial, Epigramas (Institución Fernando el Católico, Zaragoza 2003) 26.

122 Cf. C. PÉGuY, Lettre du provincial, en CEuvres en prose complètes I, 288; Clio, Dialogue de l'histoire et de l'âme païenne, 1005. Cf. Gaudium et spes 1: "Nada hay verdaderamente humano que no encuentre eco en los cristianos".

123 C. Moeller, Sabiduria griega y paradoja cristiana, 17; 21.

124 C. PÉguY, Note conjointe sur M. Descartes, 1340.

125 C. PÉguy, "Cahiers", VIII, XI, 3.2.1907, en Euvres en prose complètes II, 657.

126 O. González de Cardedal, Cuatro poetas desde la otra ladera. Unamuno, Jean Paul, Machado, Oscar Wilde (Trotta, Madrid 1996) 13. 
das como uno de los loci theologici de que la teología puede enriquecerse. A este propósito, nos parece apropiado utilizar - para una cierta teología que recae a menudo en un historicismo estéril- estas expresiones de Péguy acerca de la utilización teológica de un procedimiento-método de arte: "En un verso de Homero, en una palabra, puedes alcanzar una revelación acerca de las más augustas profundidades del mundo antiguo. Tú puedes recibir, puedes encontrar en el corazón de Sófocles una iluminación repentina" 127 .

En la antigüedad clásica la teología puede encontrar estas "revelaciones" de un pensamiento conveniente a la Revelación hebreo-cristiana ${ }^{128}$ que constituyen un aporte "no oficial" a la venida de Cristo. De hecho, como escribe Péguy,

habría que preguntarse si Dios, el Padre, no ha preparado para su Hijo, además de las referencias oficiales [los hebreos], las referencias oficiosas (officieuse) [las de la antigüedad pagano-clásica] y si el gran Rey, el Hijo, no ha sido en realidad precedido por dos cortejos (...) si no ha recibido como Rey dos tributos, en especial de pueblos que no habían creído enviárselos (...) La vocación temporal y espiritual de Grecia y de Roma es de extrema gravedad ${ }^{129}$.

Esto significa que la fe cristiana y la teología deben reconocer que no solo Israel, sino también Grecia y Roma "han aportado al Creador un fruto propio y no intercambiable" 130 . En este sentido, la lección de Péguy puede alentar para que la fe cristiana y la teología prosigan en este trabajo de lectura y de coronación del "fruto propio" aportado a Cristo por la puréte de la antigüedad clásica.

127 C. PÉGuY, Clio, Dialogue de l'histoire et de l'âme païenne, 1151.

128 Se ha escrito: "La literatura es una propedéutica que se une al cristianismo en su aspecto de revelación”: C. Moeller, Sabiduría griega y paradoja cristiana, 23.

129 C. Péguy, L'Éve de Péguy, 1232-1233.

130 C. Péguy, L'Ève de Péguy, 1232. 